The Canadian Journal for the Scholarship of Teaching and Learning

June 2016

The Role of Faculty in Connecting Canadian Undergraduate Arts and Humanities Students to Scholarly Inquiries into Teaching: A Case for Purposeful Experiential Learning

Ginny R. Ratsoy

Thompson Rivers University, gratsoy@tru.ca

http://dx.doi.org/10.5206/cjsotl-rcacea.2016.1.2

Recommended Citation

Ratsoy, G (2015). Bringing Canadian undergraduate students inside the Scholarship of Teaching and Learning through Purposeful Experiential Learning. 


\title{
The Role of Faculty in Connecting Canadian Undergraduate Arts and Humanities Students to Scholarly Inquiries into Teaching: A Case for Purposeful Experiential Learning
}

\begin{abstract}
Increasingly, various sectors of Canadian universities are advocating an assortment of beyond-the-classroom learning models - from research assistantships through service learning and cooperative education placements. At the same time, faculty who engage in the Scholarship of Teaching and Learning (SoTL) and related inquiries into teaching and learning are striving to shift attention on their activities from the periphery to a more central position within campus culture - a particular challenge for Arts and Humanities professors, who may find themselves marginalized within SoTL. This article focuses attention on the intersections of experiential learning and SoTL and SoTL-related activity. Students have much to benefit from, and offer to, these activities - beyond their usual role as subjects of studies. I present a framework based on examples from research and my own experiences - with a focus on undergraduate Arts students, who, arguably, have the fewest opportunities for Experiential Learning in general - that illustrates varying degrees of involvement. As Arts faculty attempt to enhance and highlight inquiries into teaching and learning, they would be wise to conjoin them with experiential learning by including students in the process and product.

Divers secteurs des universités canadiennes conseillent de plus en plus un assortiment de modèles d'apprentissage hors de la salle de classe - que ce soit par le biais de postes d'assistants à la recherche, de l'apprentissage par le service ou de stages dans le cadre de l'enseignement coopératif. En même temps, les professeurs qui sont actifs dans l'Avancement des connaissances en enseignement et en apprentissage (ACEA) et dans des domaines connexes liés à l'enseignement et à l'apprentissage s'efforcent d'attirer l'attention sur leurs activités pour les faire passer de la périphérie à une position plus centrale sur les campus - ce qui s'avère être un réel défi pour les professeurs des facultés de lettres et sciences humaines car ils se retrouvent marginalisés au sein de l'ACEA. Cet article se concentre sur les intersections de l'apprentissage par l'expérience et de l'ACEA et des activités liées à l'ACEA. Les étudiants ont grandement profité de ces activités et y ont beaucoup apporté, au-delà de leur rôle en tant qu'objets d'études. Je présente un cadre basé sur des exemples issus de ma recherche et de mes propres expériences - avec une concentration sur les étudiants de premier cycle en lettres et sciences humaines qui, et cela est discutable, ont le moins grand nombre d'occasions, en général, de participer à l'enseignement par l'expérience - qui illustrent divers degrés d'implication. Alors que les professeurs des facultés de lettres essaient d'améliorer et de rehausser la recherche en enseignement et en apprentissage, ils auraient intérêt à y ajouter l'apprentissage par l'expérience en incluant les étudiants dans le processus et dans le produit.
\end{abstract}

\section{Keywords}

scholarship of teaching and learning, experiential learning, scholarly inquiries into teaching and learning, research assistants

\section{Cover Page Footnote}

I offer sincere thanks to the many students who inspired this article. 
The purpose of this paper is to stimulate thought and action in Arts and Humanities faculty in Canadian universities on connecting undergraduate students to their learning by involving them in inquiries into teaching and learning. Students can examine educational methods and reflect on their own learning in such venues as the classroom, teaching colloquia and conferences, Scholarship of Teaching and Learning (SoTL) conferences, and SoTL Communities of Practice, and as independent researchers (with faculty supervision) on their learning.

Not all of the roles discussed herein adhere to inclusive definitions of SoTL such as "the systematic study of teaching and learning, using established or validated criteria of scholarship, to understand how teaching...can maximize learning, and/or develop a more accurate understanding of learning resulting in products that are publicly shared for critique and use by an appropriate community" (Potter \& Kustra, 2011. p. 2). Nevertheless, the various degrees of experiential learning (EL) that these models afford can play a crucial role in students' development. Not only does such involvement enhance students' skills of research collaboration, written and oral dissemination, and critical analysis, as they put them into practice in applied settings, but it also assists in recognition of their skill development. Partnerships with faculty in teaching-related inquiry result in expanded pedagogical understanding, and, particularly for student development, metacognition is significant (Felten et al., 2013, p. 65). High-impact EL can result from a wide range of these partnerships.

Faculty involved in such models gain assistance, meaningful mentoring experiences, and enhanced credibility for their scholarship. Enhanced credibility is important for all SoTL practitioners as they strive to embed SoTL in the culture of their campuses; however, it is particularly significant for Arts and Humanities faculty, who are often on the margins of the social sciences-dominated "discipline" of SoTL (Potter \& Wuetherick, 2015, p. 2).

Arts and Humanities students have much to offer to SoTL. As they practice the communication and critical thinking skills that are the foundations of their studies, the historical, philosophical and literary perspectives they offer can enrich and broaden the discourse around teaching and learning.

By sharing some of my experiences with, and observations of, student-engaged SoTL and other teaching-related inquiry, I hope to encourage similar models and further research. As a literature professor, I know that students in Arts, perhaps especially the Humanities, may have fewer opportunities for EL than their counterparts in, for example, Business and Sciences (where internships, co-op programs, or research assistantships may be embedded in programs). I will supplement my overview of student participation in these models with examples from recent research in order to offer insight into the breadth and depth of possibilities that can accommodate varying student needs.

\section{Rationale}

Recent strategic plans and studies indicate that the Canadian university community is increasingly cognizant of the importance of varied learning models that see students transcending the four walls of the classroom and interacting with diverse communities. Whether the rationale is preparation for graduate and professional schools, career readiness, lifelong learning, or engaged citizenship (or all of these, along with recruitment and retention), the efficacy of what is variously called "real-world experience" and "experiential learning" is in the post-secondary limelight.

Trent University's Strategic Mandate (2014) supports EL and engagement with, and contributions to, local, national, and global communities (p. 2), and the University of Guelph's Strategic Mandate (2014) highlights the percentage of its students who are volunteers, new and 
existing programs with experiential and applied components, and community research opportunities (p. 4). The University of British Columbia, "applying new research on education," emphasizes opportunities such as research assistantships, internships, international experiences, and community service learning (UBC plan, 2012). The Higher Education Quality Council of Ontario's (HEQCO) 2014 report (Lenton et al., 2014) on a two-year study of York University students' service and community-based learning, written partly in response to growing university commitment to experiential undergraduate education, found that community-based and community service learning courses enhanced students' engagement, ability to apply theory to practice, and career development (p. 6).

Although EL engagements vary considerably in form, length, and intensity, most professors are aware of the value to students of beyond-the-classroom experience, especially if we acknowledge the holistic theories of Kuh, Branch, Douglas, Lund and Ramin-Gyurnek, (1994) that all of students' experiences - academic and extracurricular and inside and outside of the classroom - are significant to their integrative changes (p. 7). Many know, as Kuh's (2013) research has also shown and the HEQCO study verifies, that these high-impact models often result in deep learning, enhanced social and personal development, and improved practical competencies (p. 87). A range of EL models is being employed to increase opportunities for Canadian undergraduate students.

One group of engaged Canadian students has published its vision for EL that is at once more collaborative and individualized. An article by fourteen Canadian university students provides a pithy view of learners' perspectives on "(re)designing the future of post-secondary education" (Demenoff et al., 2013, p. 142). Advocating "progressive education," these mainly undergraduate students advocate learning beyond textbooks, interdisciplinary approaches, linking scholarship with extracurricular activity, promoting social justice, and research with community applicability (p. 143). The writers embrace holistic learning, creativity, and erasure of traditional academic boundaries, calling for individualistic learning plans and academic recognition that postsecondary students are not leaders in training, but leaders. No longer considered an option for select students, EL is becoming an integral part of university education - requisite. Not surprisingly, this article ensued from an invited plenary session at the 2012 Society for Teaching and Learning in Higher Education (STLHE) conference, and, thus, appeared in Collected Essays on Learning and Teaching (CELT); both STLHE and CELT exist to enhance teaching and learning in higher education.

However, the natural conjunction of SoTL and other forms of inquiry into teaching and learning and student EL is often overlooked: the well-constructed beyond-the-classroom learning opportunities which these initiatives foster can transform students as much as community-engaged or traditional discipline-specific models. Hutchings (2010) notes,

One of the most powerful lessons of [SoTL] work over recent years has been the value of involving students - both undergraduate and graduate - ... not (or not only) as objects of study, but as participants in exploring and shaping their own learning. (p. 69) (emphasis added)

Students move beyond their roles of subjects in the assessment of new teaching strategies to become partners in the process of enhancing their (and their fellow students') learning experiences in a dynamic Mihans, Long, and Felten (2008) call "power sharing through collaboration" (p. 4).

Faculty increasingly recognize the value of involving undergraduate students in disciplinespecific research. Healey (2005) advocates inquiry-based classroom learning, arguing that students 
benefit most from research when they are actively involved (p. 183). Dotterer (2002), who works with undergraduate students as junior partners in collaborative projects, is among "an evergrowing number of academics" who "see undergraduate research as the pedagogy for the twentyfirst century" (p. 81). Dotterer depicts this research in a context applicable to the SoTL; it "combines teaching and research - two historic poles of a professional dichotomy - into one integrated pedagogy ... a new "vision" that scholarship and teaching may not be as separable as conventionally thought" (p. 81). That Dotterer's observations are as relevant to SoTL as they are to undergraduate research is unsurprising; the increasing practice of the former has been parallel to the increasing popularity of the latter over the past few decades.

It is, therefore, puzzling, that, if the dearth of literature on this subject - particularly in the Canadian context - is an indicator, undergraduate student involvement in SoTL and related research projects is uncommon. Such participation affords students distinct, often interdisciplinary, skill-building EL and provides faculty with a wider spectrum of research resources.

Arts and Humanities undergraduates, particularly at the senior level, have ideal research skill sets for such collaboration. Well versed in the basics of research in several disciplines and conversant with multiple citation styles, they are likely to adapt to training in SoTL and related methodology. McKinney, Jarvis, Creasey and Hermann (2010) observe that the "real benefits.... are the perspective and insights students bring to SoTL" (p. 89). As well as contributing their skill set, students are compensating for an unavoidably limited faculty point of view.

For students, work with faculty on SoTL projects can be invaluable. It affords an additional perspective from which to view their learning, and a hands-on experience - applying classroom theory - results in improved research and writing (McKinney et al., 2010, p. 83). As well as building résumés, the experience hones practical skills for future graduate and professional schools and workplaces. McKinney et al. (2010) report that undergraduate student research involvement with faculty increases retention and encourages pursuit of graduate education (p. 83).

Furthermore, these students can become allies in the movement to increase campus understanding of and institutional support for the practice of teaching inquiry. SoTL has not been without its detractors and mis-interpreters, and SoTL practitioners have recounted institutional obstacles. In the Canadian context, Kenny and Evers (2010) discuss five challenges that student participation may alleviate: (a) the number of faculty practiced in SoTL may be small; (b) often faculty do not have education in teaching; (c) confusion over the terms "scholarship of teaching and learning" and "scholarly teaching": a belief that reading literature about teaching constitutes practicing SoTL; (d) institutional funding for SoTL may be scarce, and promotion and tenure documents may not recognize it; and (e) with teaching, service, and discipline-specific research responsibilities, faculty may think they have no time for SoTL (pp. 21-26). By involving the raison d'etre for SoTL - indeed, the raison d'etre for our institutions - in meaningful ways into our practice, are we not spreading knowledge about teaching inquiries, educating students about their learning, alleviating time constraints, and cultivating ambassadors for teaching-focused inquiries? Is not such involvement especially beneficial to Arts and Humanities faculty, who have the additional challenge of coping with social science conventions as they engage in teaching inquiry? (Potter \& Wuetherick, 2015).

As faculty members strive to integrate SoTL into campus culture, we have the opportunity - and obligation - to move students from the periphery into the picture. As Hutchings and Huber (2010) state, such involvement "brings the scholarship of teaching and learning full circle" (p.xiv). Fortunately, we have at our disposal numerous fertile sites for reciprocal exchange about SoTL, 
without which, as Werder and Otis (2010) remark, "a monologue about teaching and learning results" (p. 29).

The following examples of student involvement in SoTL are organized according to the depth of involvement in teaching and learning inquiry, in ascending order:

- Peripheral involvement: Students are initiated into the practice through, first, classroom discussion and assignments and, then, organizing and attending teaching-related presentation series, colloquia, and conferences. While not necessarily formally researching teaching and learning, students are being introduced to an aspect of university culture otherwise alien to them, networking, and practicing classroom skills in a teaching and learning environment. Students have the potential to evolve from outside observer to attendee to contributor. They are receiving an introduction to EL.

- Collaborative SoTL involvement with faculty: Students work with faculty in Communities of Practice. As such, the impact of the EL is high; the range of skills developed and honed is widened, and the depth of involvement is increased over the peripheral model.

- Supervised independent SoTL research: Students devise and create a SoTL project, enabled by a university- supported research program and facilitated by faculty. Arguably, EL has its highest impact when students undertake such a learning project.

\section{Peripheral Involvement}

Classroom culture. Felten et al. (2013) maintain that all students need information about the benefits of their involvement in SoTL (p. 68). Arts and Humanities faculty can lay the groundwork for student inquiry into the construction of their learning - regardless of the course in various ways.

Learning-focused class discourse is an important first step. Discussing approaches to learning, encouraging informal feedback on teaching styles and assignment formats, and explaining the implications of formal institutional feedback are within the parameters of all classrooms. Although students may initially be reluctant to reveal personal learning approaches or judge their professors' teaching styles, a few minutes of class time regularly devoted to such issues can benefit professors' pedagogy, increase students' awareness of the intricacies of teaching and learning, and contribute to openness in the classroom.

Course curricula can be adapted to promote student understanding of teaching and learning. For example, assignment sheets with clear rationales, pre and post- discussions of assignments, and required readings related to teaching and learning can expand students' comprehension of their education.

Reflective assignments are a further tool to enhance students' awareness about their learning. The personal involvement required can stimulate students' metacognition and confidence in their scholarly roles, and, according to Felten et al. (2013), increase "their confidence to engage in SoTL initiatives" (p. 68). Assignments that encourage students to teach others - instructional videos and blogs, and writing centre placements, for example - that also require reflective writing can take a further step to increasing learning awareness and serve as both introductions to SoTL and samplers of EL.

Creative reconceptualising of courses to consciously promote students' examination of their education and incorporate EL assignments can be impactful for Canadian Arts and 
Humanities students. For example, I was delighted to see included in the 2016 program of an undergraduate student conference at my institution, organized by Humanities students, a panel, "Innovative Pedagogies" featuring history and English students' papers.

Co-organizing teaching series, colloquia and SoTL conferences. In my work organizing a weekly series of presentations about teaching, student collaboration proved mutually beneficial. As faculty receive assistance and mentoring experience, students practice low-risk approaches to enhancing and applying their learning. Arts and Humanities students, for example, hone the oral, written, and visual communication skills they have developed in their studies through interactions with supervising and presenting faculty, scheduling of speakers, and creation of publicity material. The supervisor-learner roles can be reversed if the students have greater experience with social media for publicity purposes: students can make meaningful contributions to the process of organization and the success of the series. In more visible roles, even such seemingly minor functions as organizing refreshments and introducing speakers are low-risk opportunities for students to enhance their organizational abilities, self-confidence in public speaking, and networking.

Although these roles may be peripheral to SoTL itself, they have considerable transferability - to student club or other extracurricular settings, for example - and are perhaps particularly valuable to Arts and Humanities students because they provide them with the opportunity to practice and value the "soft skills" sometimes undervalued in higher education today. While the applicability of these skills is most evident to prospective education and graduate school students, they are also relevant to other professional schools and the workplace itself. Furthermore, they can be stepping stones toward greater involvement in the discussion of teaching and learning and, thus, enhanced comprehension of the significance and complexity of scholarship.

Students' awareness of their professors' commitment to student learning is enhanced as they receive behind-the-scenes perspectives on how their learning is constructed-practical demonstration of theoretical concepts. Results may include the recognition of educational theories, insight into signature pedagogies, and perception of common ground among disciplines. The culture of the academy is more visible for students who have roles in organizing teaching presentations.

SoTL conferences and teaching practices colloquia or conferences offer similar opportunities for students to develop event planning and publicizing skills. Social learning that takes place over the course of a year of conference organizing is likely to be deep learning. The theories (based on research findings) of Kuh et al. (2005) that "many experiences outside of the classroom put the student at the center of learning, demanding that students test their skills and values" (p. 6) are particularly applicable to the conference setting. Working to deadline in a "reallife" academic setting is a type of testing with which the undergraduate Arts student is likely to have limited familiarity.

The importance to students of working with faculty and having a say in decision making cannot be overstated - whether the decision be related to scheduling, social media platforms, catering choices, or more complex matters. Kuh et al (2005) report that studies reveal that advanced students "prefer interactions with faculty during which faculty treat students as partners in constructing knowledge" (p. 27). Faculty committee members should reflect on the mentoring possibilities inherent in these situations, which provide low-risk introductions to EL.

Attending and participating in teaching-related series, colloquia, and conferences. Students who assist with organizing and publicizing are well served by regular attendance at teaching-focused events. Student presence is advantageous to organizers and presenters, and the 
presentation site is an ideal context for situated learning, the theory popularized by Lave and Wenger (1991) that the learner, rather than a receptacle for "factual knowledge" to be deposited into, is a "whole person" whose "comprehensive understanding" is emphasized. Situated learning theory centres on "activity in and with the world" (p. 33) - interactivity for holistic growth.

In faculty development series, students can take notes, gather statistics, and, if they regularly attend, be "sounding boards" for faculty to test new ideas. They can become representative students with meaningful voices in the SoTL work of the presenters and attendees - while receiving hands-on communication training and having a rare pan-disciplinary adventure. As Manor, Bloch-Schulman, Flannery, and Felten (2010) note, student involvement in SoTL empowers students as it increases their sense of responsibility for their education (p.11).

A weekly series of faculty presentations that I co-organized over a two-year period presents a salient illustration. Although our vision of the series limited student involvement to assistance with organizing, students gradually began to attend the presentations of their own volition. Whether supporting their presenting professors and fellow students, dropping in on a session on a topic germane to their studies, or attending regularly out of general interest, the students received a taste of the SoTL experience - an introduction to "the other side" of their learning -- as well as a perspective on EL. After witnessing faculty enthusiasm for pedagogical examination, these students made meaningful contributions to the ensuing discussions.

Furthermore, "one-offs," such as colloquia and conferences, afford students quick, yet immersive, glimpses into the construction of their learning. A taste of a culture they otherwise know little about could engender greater involvement in the study of their teaching and learning.

\section{Collaborative SoTL Involvement with Faculty}

Co-presentations in series, colloquia, and conferences. In the weekly teaching presentations on EL that I co-organized, publicizing the fact that a talk would be given by a faculty member and a student who had experienced the teaching technique the professor had initiated catalyzed a change in the culture. Attendance rose, the student newspaper took notice, and faculty attendees were keenly interested in the student presenter's insights.

Within a year, students were co-presenting on an array of their classroom and beyond-theclassroom experiences - from unconventional assignments in a traditional course to community service learning placements. By sharing their experiences with the campus, the students were modelling the EL espoused by the participating professors, gaining applied oral presentation experience, and providing and receiving knowledge into learning construction.

Co-presentation at teaching colloquia and SoTL conferences offers similar mutual benefit. The preparation process has an added dimension when the professor has the opportunity to closely examine a technique or theory with a student who has actually experienced the approach. At the presentation itself, students tend to be the focus of attention: faculty attendees often look to the students for verification of the efficacy of the teaching practice the professor is advocating. Sessions with student co-presenters hold the promise of being particularly engaging precisely because the professor has taken the time to involve students in the process of creating them. Finally, feedback from students with whom I have co-presented indicates their appreciation for the opportunity to apply their presentation skills to an audience to whom they are more often listening, rather than sharing with, and gratitude for witnessing professors' enthusiasm for the construction of student knowledge. Faculty should be reminded that "students change as whole, integrated persons; virtually all of their academic, non-academic, in-class, and out-of-class experiences are 
potentially important to these changes" (Kuh et al., 2005, p. 7) - and that professors can have profound roles in those changes.

Students have a specific EL experience; the presentation experience, which cannot be duplicated in the classroom, adds to their academic skill sets, enhances their résumés, intensifies their identification with university culture, and deepens their metacognition. Arts and Humanities students are perhaps particularly well served by such involvement, because it can serve to highlight the importance of their learning at a time when their disciplines may be perceived as impractical, and because enhanced self-confidence results when students realize that their perspectives on learning are valued by educators from across disciplines. Presentation series, colloquia, and conferences are fertile fields for student inquiry into teaching and learning.

Research assistants in communities of practice. Williams et al., (2013) acknowledge that the approaches of SoTL practitioners can be misunderstood, even resisted, by other faculty and administrators (p. 51). They maintain that SoTL must make an impact at all institutional levels "because it is essential ... because improving the quality of students learning requires an evidencebased approach" (p. 50) and advocate communities of practice (among other things) to overcome barriers to full institutional support, seeing them as social networks (p. 54).

Communities of practice, originally developed in 1991 by Jean Lave and Etienne Wenger while they were studying the apprenticeship model, have been used in such professions as business, international development, and education as a means to strengthen performance (Wenger-Trayner \& Wenger-Trayner, 2015). The Wenger-Trayners (2015) frame communities of practice around domain, community, and practice. Group members who share competence in and dedication to a particular field relate through shared activities, discussions, and resources. (p. 2). Over time, the collaboration advances knowledge in the field, producing new ideas, practices, and resources.

SoTL Communities of Practice (CoP's) where faculty establish discussion and working groups around a specific theme in order to inquire into and improve their teaching - and, therefore, student learning - are ideal settings for undergraduate Arts students to apply their broad skills and knowledge. Students receive insiders' perspectives into how their learning has been constructed and the rare opportunity to work on something they are simultaneously experiencing - and influence how it may be taught in the future.

Ryser, Halseth, and Thien (2009) report that students rarely grasp interdisciplinary research skills in the confines of the classroom; EL models are much more effective (p. 249). As SoTL often crosses disciplinary boundaries, it provides an opportunity for the student to draw upon and integrate knowledge acquired in various disciplines while extending knowledge about teaching practices into new areas. The SoTL CoP can foster increased meta-cognition as students make personal connections across their course of study.

Faculty teaching in varied disciplines may, for example, complete a study on how a specific thematic approach can be applied in an interdisciplinary context or investigate the effects of a similar assignment on students in their courses. Research assistants, who may be some of those students, can collect and analyze data and assist in a literature review. As Mihans et al. (2008) note, student engagement in SoTL data collection and analysis means "fresh eyes and keen insight," as faculty, who, with greater expertise, take the lead, but also heed student viewpoints (p. 7). Student partners receive training in academic workplace conventions as they apply knowledge acquired in a variety of disciplines and share decisions about emerging themes. Such partnerships have the potential to raise the profile of the SoTL project, particularly if faculty encourage conference co-presentation and joint authorship of articles. Undergraduate Arts students, whose 
education is broad by design, are well-suited to a project that requires diverse skills. As research assistants in CoP's they provide insiders' perspectives - they not only have "been there" but they are there - and bridge the gap between faculty perceptions of their teaching and student perceptions of their learning. In short, the impact on students of an EL placement as research assistant on a SoTL project is considerable.

\section{Independent SoTL Researchers with Faculty Supervision}

University supported research programs. EL that involves students in creating and completing SoTL-related projects is likely to be the most transformative. Cook-Sather, Bovill and Felten (2014) provide several examples in the United States, the United Kingdom, and Australia of entire programs designed for undergraduate students to complete the research process, with faculty supervision, on SoTL projects. They note that such approaches broaden educational horizons: they "allow us to glimpse new possibilities for the purposes and practises of higher education" (p. 95).

At the University of Western Australia, for example, an internship program invites undergraduates to receive basic research methods training from a supervisor and then select from topics, such as sustainability, internationalization, and the first-year experience, the university considers of strategic significance. Students devise their own research questions and design approach, collect and analyze data, and write an academic paper to be disseminated internally and externally. Participants' responses have been favourable; students find SoTL research personally beneficial, better understand institutional constraints, and find the "lecturer-student gap" closing (p. 79).

Considerable institution-wide support is required to implement entire programs devoted to student-SoTL research; one hopes that, as SoTL becomes more established in Canada, research on such programs will emerge. However, Canadian universities may currently support programs for individual student research projects that lend themselves to a SoTL approach - grants that fund successful applicants to complete original research projects with faculty supervision. The first impulse of faculty may be to encourage discipline-specific research that ensues from an interest generated in a specific course; however, a rethinking is encouraged. The considerable number of undergraduate students anticipating careers as teachers, considering graduate school, or with an interdisciplinary interest, may be better served by SoTL projects. As in the project at the University of Western Australia, students may follow issues of strategic importance to the university if they intersect with their interests or study plans.

For example, study abroad-focused research that gauges the student body's interest in internationalization as it overlaps with the student researcher's own plans to study abroad or do graduate work in International Relations could involve the researcher in a campus' international unit, as well as in interviewing faculty and students. Arts and Humanities students could provide historical, philosophical and gender perspectives, as well as critical analyses of relevant literature. Such projects could broaden the students' research skill sets, particularly if a requirement is public presentation. The paper could be distributed to study abroad and student union personnel. This type of project has networking potential and an immediacy that is difficult to duplicate in discipline-specific research.

A veteran of a co-op placement or service learning course, for example, also has the opportunity for meta-cognition by developing a research question about EL - or a certain model of EL - and its potential for engagement on campus. Here again, the student - who is both expert 
and novice - engages in varied research, transcends traditional disciplinary boundaries, and studies something in which she or he has been engaged. In both examples, the research could have measurable impact: it could influence policy.

Arts and Humanities professors who embrace the possibilities of this one-on-one mentoring to encourage scholarly inquiry into teaching and learning are also broadening the horizons of SoTL. As Potter and Wuetherick (2015) remind us, the research approaches used in the humanities can result in a depth of understanding that the social sciences cannot ignore (p. 6). The nuances of qualitative research, of close reading, of narrative, and of ethnography, for example, can be captured by Arts researchers. Particularly as education programs and graduate schools - where students may become teaching assistants with little pedagogical preparation - are often the goal of undergraduate Arts students, Arts professors would serve themselves, the culture of SoTL on their campuses, and, above all, their students, well by reflecting on methods of engaging students in education-focused studies.

\section{Meeting Challenges}

As with any change, faculty attempts to amplify student inquiries into teaching and learning are bound to encounter obstacles. Transforming, or even modifying, existing structures is more challenging than reifying those structures.

Not the least of these challenges is time. If, as Kenny and Evers (2010) report, an obstacle to SoTL growth in Canadian universities is that other responsibilities may lead faculty to conclude that there is little time for scholarly inquiries into teaching (p. 26), the commitment to initiating students into those inquiries may appear overwhelming. However, the complementarity of teaching and research makes SoTL practical. Teaching can generate scholarly output, rather than compete with it; therefore the integration SoTL offers can be an economy. The time required to recruit and coach students can be more than compensated for by their assistance and the professional satisfaction faculty can obtain from the collaboration. Institutional recognition of the time required for such faculty mentoring is also crucial - and justifiable as EL is increasingly prominently featured in strategic plans. Students, too, often have time constraints. While it is likely unrealistic to imagine all students fully participating in an outside the classroom SoTL project, the goal of all students inquiring into teaching and learning, to some degree, is, I maintain, realistic.

Hutchings (2003) sees SoTL is a "cousin" to the undergraduate research movement (p. 32). As students increasingly seek EL opportunities, collaboration on SoTL provides the experience of "investigat[ing ] and build[ing] knowledge about important issues in the field" (Hutchings, p. 33). Students who are seeking EL opportunities can be well served by SoTL collaborations.

As relationships in which one partner is perceived as the authority, SoTL collaborations with students are delicate and complex. Allin (2014) asserts that "true collaboration with students is not easy to achieve" because of deep-seated institutional power relations (p. 96). Allin maintains that the professor, with greater power and expertise, should be constantly on guard against presuming student intent and misinterpreting student perspectives, for instance (p. 97). Her article concludes with a call to action and a solution: engage students as more than sources of data; encourage deep involvement "with associated empowerment and potential for change" (p. 100). By making no assumptions, listening, and seeking opportunities for meaningful involvement of students in learning inquiry, faculty can make inroads into levelling the power relationship.

Both institutional and faculty initiatives in the development and fostering of EL models are critical to engaging students in scholarly inquiry into learning. Work-study positions, in which 
students who demonstrate financial need are paid to work on campus, can play important roles in initiating students into teaching and learning sites that explore the construction of their learning. Special topics and directed studies courses can also accommodate diverse projects and needs. Service Learning - community and academic - is applicable to many of the models discussed above; it is a flexible model which can consist of a single assignment within a course or an entire course, allowing for peripheral or sustained involvement. Institutional awards for student research collaboration - which fully acknowledge SoTL as a viable approach - are also requisite. A variety of EL models that provides diverse rewards to students with an assortment of interests can go a long way to meeting the challenges of engaging students in SoTL and other teaching inquiries.

\section{Conclusion}

This discussion of involvement in SoTL activities is but a sampling of the possible models of EL. It is meant to be generative, not prescriptive. In the spirit of the SoTL, its intention is to stimulate increasing undergraduate Arts and Humanities student SoTL and SoTL-related involvement at Canadian universities - and further the study of this rich topic.

The three-stage involvement I outline - peripheral, collaborative and independent - is but one paradigm for student involvement in learning inquiry. Readers would be well served to consult a taxonomy devised by McKinney et al. (2010) that lays out eight roles of increasing complexity for students in SoTL, ranging from research subjects to independent researchers, and analyzes the autonomy, activity, complexity, and interactivity each role provides (p. 85). Consulting multiple blueprints for the complex undertaking of involving students in learning inquiry maximizes potential.

Having supervised projects in which students were engaged on various levels, I have observed that some students prefer skimming the surface of possibilities before committing to more complexity. It is useful to remember that a project that begins with peripheral involvement can transform into something that requires more sophisticated student participation. I have also noted that students who opt for one inquiry-based EL placement often opt for more. Individual faculty supervisors may face the temptation to re-engage the same students in their work, rather than seeking new recruits - although the other side of that is that repeated EL SoTL-related placements can result in the individualized learning plan advocated by the fourteen authors of the CELT essay. As a professor, I have found SoTL both compelling and empowering; I have observed a similar response in students.

I recommend that, regardless of the depth of student involvement in learning inquiry, faculty encourage students to publically disseminate their work and distribute it to a wider audience. In addition to facilitating the spread of SoTL, dissemination raises students' selfconfidence. Whether through a student undergraduate conference, a guest lecture in a class, a teaching and learning centre workshop, or a peer-reviewed conference on or off campus, when students co-present, their belief in the significance of their research is affirmed by the audience's interest in it. A wider readership for assignments has a similar effect. Dissemination makes manifest to students their membership in a community of inquirers into learning.

Allin (2014) reports on co-presentation at a SoTL conference with a newly graduated student. The student was the only non-faculty delegate, received most of the questions and favourable feedback, and indicated that, had she known of the existence of conferences where faculty discussed students' learning, "she would have been much more actively involved in her learning whilst at university" (p. 100). This response points to a significant gap: even students who 
have peripheral knowledge of SoTL may be unaware of possibilities for more profound, transformative engagement.

McKinney et al. (2010) report that faculty-student research partnerships have a more holistic effect on student development than typical classroom research experiences (p. 84). Even the less involving peripheral examples I discuss offer greater potential for student development than typical classroom experiences - falling into the high impact category Kuh (2013) espouses. However, we should remember that the seeds of that involvement can be planted in the classroom.

McKinney et al. (2010) also report that, although existing studies indicate increased retention, enhanced confidence, and greater likelihood of pursuing graduate education in students because of their EL experiences, more research into student involvement in SoTL, specifically, is needed (p. 84). This essay addresses a relatively small number of examples of individual students' engagement in SoTL and related scholarship. Larger studies, both qualitative and quantitative, would be valuable. For example, if entire programs for student SoTL involvement exist in Canadian universities, dissemination about their structure and efficacy could provide a meaningful template. If a particular model - research assistantships, for example - is predominately used for SoTL collaboration at a particular institution, researchers would be making a valuable contribution to the literature by disseminating their findings.

If, as Hutchings (2010) maintains, SoTL must make an impact at all institutional levels to be sustainable at the campus level (p. 2), establishing a campus culture of SoTL is a tall order. If, as Potter and Wuetherick (2015) indicate, SoTL is being directed by the social sciences, the challenge for Arts and Humanities faculty is particularly acute. What better allies can we enlist than the reasons for our inquiries in the first place - our students? Above all, at a time when the Arts and Humanities are being de-emphasized, we owe it to our students to engage them in highimpact activities that demonstrate the relevance of their studies.

The time is ripe for Arts faculty to make concerted efforts to bring undergraduate students inside of their learning. The CELT article and the increasing attention to EL in universities' strategic mandates indicate that Canadian students' requests for hands-on experiences will proliferate and universities will respond. As these trends intersect with increasing demands on SoTL practitioners in general and Arts and Humanities faculty in particular to provide concrete proof of SoTL's efficacy, there is no time like the present to foster collaboration for mutual benefit.

As Werder and Otis (2010) remind us, students inform, inspire, and sustain our scholarship (p.187). Never is this more the case when we involve them directly in that scholarship. We have an obligation to expand the role of the reasons for our inquiry beyond that of subject. Above all, as Mihans et al. (2008) attest, SoTL on which faculty and students partner can be transformative - for all parties.

\section{References}

Allin, L. (2014). Collaboration between staff and students in the Scholarship of Teaching and Learning: The potential and the problems. Teaching and Learning Inquiry 2(1), 95-102. http://dx.doi.org/10.20343/teachlearninqu.2.1.95

Cook-Sather, A., Bovill, C., \& Felten, P. (2014). Engaging students as partners in learning and teaching: A guide for faculty. San Francisco: Jossey-Bass. 
Demenoff, S., Genest-Richard, P., Labbé, J., Bourgault, R., Lewis, J., Robinson, A., Pritz, J., Bell, C., Beach, L., Beaupré-Lavallée, A., Barudin, J., Charles Howard, R., Liu, M., \& Nichols, S. (2013). Blind curves or open roads? Student leaders speak on the future of Canadian post-secondary education. Collected Essays on Learning and Teaching, 6, 142-146.

Dotterer, R. L. (2002). Student-faculty collaborations, undergraduate research, and collaboration as an administrative model. New Directions for Teaching and Learning, 90, 81-89. http://dx.doi.org/10.1002/tl.58

Felten, P., Bagg, J., Bumbrey, M., Hill, J., Hornsby, K., Pratt, M., \& Weller, S. (2013). A call for expanding inclusive student engagement in SoTL. Teaching and Learning Inquiry, 1(2), 63-74. http://dx.doi.org/10.20343/teachlearninqu.1.2.63

Healey, M. (2005). Linking research and teaching to benefit student learning. Journal of Geography in Higher Education, 29(2), 183-201. http://dx.doi.org/10.1080/03098260500130387

Hutchings, P. (2003). Competing goods: Ethical issues in the scholarship of teaching and learning. Change (September/October), 27-33. http://dx.doi.org/10.1080/00091380309604116

Hutchings, P. (2010). The scholarship of teaching and learning: From idea to integration. New Directions for Teaching and Learning, 123, 63-72. http://dx.doi.org/10.1002/tl.410

Hutchings, P., \& Huber, M.T. (2010). Foreword. In Werder, C., \& Otis, M. (Eds). Engaging student voices in the study of teaching and learning (pp. xi-xv). Sterling, VA: Stylus.

Kenny, N., \& Evers, F. (2010). Responding to the challenging dilemma of faculty engagement in research on teaching and learning and disciplinary research. Collected Essays on Teaching and Learning, 3, 21-26.

Kuh, G. (2013). Promise in action: Examples of institutional success. New Directions for Higher Education 161, 81-90. http://dx.doi.org/10.1002/he.20048

Kuh, G., Branch, D., Douglas, K., Lund, J., \& Ramin-Gyurnek, J. (1994). Student learning outside the classroom: Transcending artificial boundaries. Washington, DC: ERIC Clearinghouse on Higher Education.

Kuh, G., Kinzie, J., Schuh, J., Whitt, E., \& Associates. (2005). Student success in college: Creating conditions that matter. San Francisco: Jossey-Bass.

Lave, J., \& Wenger, E. (1991) Situated learning: Legitimate peripheral participation. Cambridge, UK: Cambridge University Press. http://dx.doi.org/10.1017/CBO9780511815355

Lenton, R., Sidhu, R., Kaur, S., Conrad, M., Kennedy, B., Munro, Y., \& Smith, R. (2014). Community service learning and community-based learning as approaches to enhancing university service learning. Toronto, ON: Higher Education Quality Council of Ontario.

Manor, C., Bloch-Schulman, S., Flannery, K., \& Felten, P (2010). Foundations of student-faculty partnerships in the scholarship of teaching and learning. In C. Werder \& M. M. Otis (Eds.), Engaging student voices in the study of teaching and learning (pp.3-15). Sterling, VA: Stylus.

McKinney, K., Jarvis, P., Creasey, G., \& Herrmann, D. (2010). A range of student voices in the scholarship of teaching and learning. In C. Werder \& M. M. Otis (Eds.), Engaging student voices in the study of teaching and learning (pp. 81-95). Sterling, VA: Stylus.

Mihans, R. J., Long, D. T., \& Felten, P. (2008). Power and expertise: Student-faculty collaboration in course design and the scholarship of teaching and learning. International Journal for the Scholarship of Teaching and Learning, 2(16), 1-9. http://dx.doi.org/10.20429/ijsotl.2008.020216 
Potter, M. K., \& Kustra, E. (2011). The relationship between scholarly teaching and SoTL: Models, distinctions, and clarifications. International Journal for the Scholarship of Teaching and Learning, 5(1), 1-18. http://dx.doi.org/10.20429/ijsotl.2011.050123

Potter, M. K., \& Wuetherick, B. (2015). Who is represented in the teaching Commons? SoTL through the lenses of the Arts and Humanities. The Canadian Journal for the Scholarship of Teaching and Learning, 6(2), 1-16. http://dx.doi.org/10.5206/cjsotl-rcacea.2015.2.2

Ryser, L, Halseth, G., \& Thein, D. (2009). Strategies and intervening factors influencing student social interaction and experiential learning in an interdisciplinary research team." Research in Higher Education, 50(3), 248-267. http://dx.doi.org/10.1007/s11162-008-9118-3

Trent University. (2014). Strategic mandate agreement between the Ministry of Training, Colleges and Universities and Trent University. Available at https://www.trentu.ca/administration/documents/20140430_SMA.pdf

University of British Columbia. (2012). The UBC plan: Student learning. Available at http://strategicplan.ubc.ca/the-plan/student-learning/

University of Guelph. (2014). Strategic mandate agreement between the Ministry of Training, Colleges and Universities and University of Guelph. Available at http://www.tcu.gov.on.ca/pepg/publications/vision/universities.html.

Wenger-Trayner, E., \& Wenger-Trayner, B. (2015). An introduction to communities of practice. Available at http://wenger-trayner.com/introduction-to-communities-of-practice/.

Werder, C., \& Otis, M. M. (Eds.). (2010). Engaging student voices in the study of teaching and learning. Sterling, VA: Stylus.

Williams, A. L., Verwoord, R., Beery T. A., Dalton, H, McKinnon, J, Strickland, K, Pace, J, \& Poole. G. (2013). The power of social networks: A model for weaving the Scholarship of Teaching and Learning into institutional culture. Teaching and Learning Inquiry: The ISSOTL Journal, 1(2), 49-62. http://dx.doi.org/10.20343/teachlearninqu.1.2.49 